\section{ESA scientific programme}

The European Space Agency is in the process of selecting its future scientific satellite and shuttle payloads. Studies of 16 possible projects were presented to European scientists at the end of last month in Paris. The astronomy and solar system working groups subsequently made recommendations and the Science Advisory Committee then listed the next scientific projects to be undertaken: cooperation on the space telescope with NASA, an out-ofecliptic and solar stereoscopy mission and a large infrared telescope on Spacelab. Final decisions will be taken in September, but UK scientists are meeting this week to identify their main areas of interest. They may also voice their objections about where the axe has fallen among the original projects.

\section{Reprocessing debate continnes}

The social, technological and environmental problems associated with the management of radioactive nuclear waste came under the spotlight last week during an international meeting of nuclear power experts in Denver, Colorado. Sir John Hill, Chairman of the UKAEA, pointing to national and international regulatory agencies, warned against premature adoption of inadequate short term safeguards on the one hand, and unnecessary delays to nuclear expansion pending the development of a "final [reprocessing] solution" on the other. Sir John foresaw no imminent changes in UK waste management policy, so that work on vitrification processes would continue, which need not ultimately preclude incineration. Even with widespread nuclear development, he said, radioactive waste arisings would be small compared with world mercury and arsenic stocks.

Meanwhile, amid reports that western Europe will have only about half of the reprocessing capacity it needs by 1980 , work has begun on the site for British Nuclear Fuels Ltd's (BNFL) new reprocessing facility at Windscale. With construction costs estimated at $£ 350$ millions (the UK Government has just underwritten BNFL borrowing of $£ 75$ millions) the installation is expected to handle 1,000 tonnes of spent fuel a year by the mid-1980s.

A call for an outright ban on the sale of the technology for reprocessing will, however, be made at the annual conference of the British Labour Party in September. A motion urges the UK Government to consult with the group of nuclear exporting countries on the matter.
THE name of sassafras tea conjures up thoughts of early days in North America, of folk medicine, and of a tree whose leaves, charmingly enough, grow in three difiesent shapes on the same branch-some are threefingered, some are mitten-shaped, and some are just oval. The name is Spanish, but the Onondaga tribe in New York State called it Wah-ehnak-kas-_"smelling stick".

Pull up a sassafras seedling. You can peel the bark from the root, and sniff at the fragrance of the core. This spicy aroma led to its use as a flavour for root beer, which is a popular soft drink well-known to Americans and Canadians. But, alas, after many generations of people had enjoyed the natural flavour of sassafras, it turned out that safrole, the substance responsible for this, caused cancer in rats. Oil of sassafras, which contains about $80 \%$ safrole, was therefore banned as a food additive in 1960.

Manufacturers of flavoring extracts switched to methyl salicylate, present in wintergreen berries, as a substitute for oil of sassafras, and root beer continued to flow wherever soft drinks were sold in North America. The change made for a somewhat linimentous tang in the beverage, but the salicylates have a clean bill of health in the field of cancer. Also, wintergreen grows beneath sassafras trees in the Appalachian woodlands, so that there was an ecological link between the old flavour and the new.

But safrole still lurked in packages of dried sassafras root that are sold in "health food" stores to lovers of herb teas. These infusions are rumoured to be good, in a generalised way, for what ails you. By sipping them, you get all the benefits of hot water plus whatever happens to be in dandelion heads, camomile, dried parsley, peppermint leaves, comfrey,

\section{Mad about safrole}

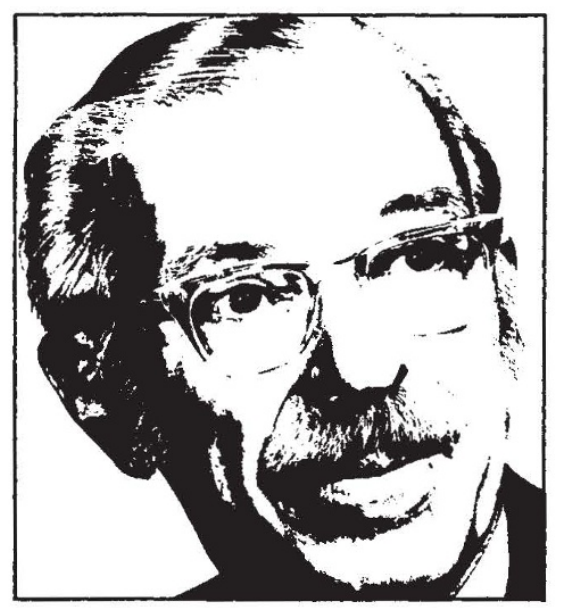

THOMAS H. JUKES

rosemary (that's for remembrance), verbena, yerba maté, and, of course, sassafras.

Since these ingredients contain hundreds of compounds that have never been biologically tested for anything, herb teas are apparently considered harmless, and in addition, their consumption is hallowed by ancient custom. Unhappily for tradition, the Commissioner of Food and Drugs sternly pointed the finger "to make it clear that the prohibition on the use of safrole in food includes safrolecontaining sassafras sold to make sassafras tea; effective June 10,
1976."

Comments had come from private citizens and people in the herb tea business. Several felt it was unlikely that sassafras tea is injurious to health even if safrole is carcinogenic, in one case because the tea is consumed in the spring, and in another because it had "been used for centuries without reports of carcinogenic or other toxic effects." Others noted that safrole was present in other foods such as nutmeg and mace and that hence the ban should include "all food substances containing detectable amounts of safrole."

This, of course, would be in accordance with the rules laid down by the "Delaney Amendment" in the Food Additives Law. The Commissioner replied, in effect, that he couldn't ban everything, and he had to take care of the most concentrated source of safrole first. One correspondent stated that the fat of charcoal-broiled steak contains carcinogens and that "action on sassafras should be deferred until something is done about that." No one mentioned cigarettes.

Several comments expressed various forms of anguish that a natural food, or food constituent, or ingredient, or component should be regulated, saying that this treatment should be reserved for chemical additives. Gently, the Commissioner reminded them that all food ingredients, including natural food constituents, are chemicals, also that the definition of "food" includes food additives.

The ban showed that sauce for the Red Dye No. 2 goose is also sauce for the sassafras tea gander. 